\title{
The National Values Impact on Organizational Change in Public Organizations in Qatar
}

\author{
Saeed Hameed Aldulaimi \\ College of Graduate Studies, University Tenaga National \\ Bangi, Malaysia \\ Tel: 60-17-653-7181Ｅ-mail: sskw20@yahoo.com \\ Md Saaid Sailan \\ College of Graduate Studies, University Tenaga National \\ Bangi, Malaysia
}

Received: August 31, 2011

Accepted: September 14, 2011

Published: January 1, 2012

doi:10.5539/ijbm.v7n1p182

URL: http://dx.doi.org/10.5539/ijbm.v7n1p182

\begin{abstract}
This paper aims to investigate the impact of Hofstede's five dimensions of national values (Power Distance, Individualism, Uncertainty Avoidance, Masculinity, and Long-Term Orientation) on commitment to organizational change and individual readiness for change.

No empirical research of the influence of national values on organizational change was conducted. Structural equation model employed in particular confirmatory factor analysis and path analysis procedures was used to test the hypothesized model.

Findings of this study offer valuable insights on why cultural values should be differentiated as they relate to different individual readiness and commitment to change. The findings of this study will be useful to the policy makers and organizations that plan to accomplish change initiatives, particularly those in Arabic region. Managers at international corporations can also benefit from this study if they have business dealings with the people from this region. The study is among the first that investigates the issue of change implementation from the perspective of national cultural values.
\end{abstract}

Keywords: National values, Commitment to change, Readiness to change, Qatar

\section{Introduction}

In the globalization era, countries attempt to apply their national strategies to support their advancement in economic, social, and human levels. According to Kotter 2003; 'leaders establish the vision for the future and set the strategy for getting there; they cause change, consequently they motivate and inspire others to go in the right direction'. Therefore organizations must understand and predict employees' psychological reactions to change because psychological reactions to a particular change influence employees' behavioural tendency toward the change (i.e., support or resistance to change) and are key issues in successfully implementing change (Chen and Wang, 2007, Klein et al., 2001 and Klein and Sorra, 1996).

When implementing organizational change, it is vital to understand that people are the most important component of change (Kesterson \& Broome, 2005). Culture has been alternatively defined as the manner in which a group of people solves problems and reconciles dilemmas (Trompenaars \& Hampden-Turner, 1998). Therefore there is a growing interest in understanding how change is experienced by individual employees (Judge et al., 1999) and researchers are beginning to investigate the role of employee commitment in organizational change situations (Herscovitch and Meyer, 2002); because employees with strong organizational commitment tend to be more productive and more willing to assume larger responsibilities (Herscovitch and Meyer 2002; Abbott et al. 2005). In addition, a previous research also implies that organizational commitment would be an important determinant of organizational change (Iverson, 1996; Fedor et al., 2006; Parish et al., 
2008). Basing on this preface, we attempt to investigate the influence of national cultural on readiness to change and consequently on commitment to change particularly in Qatar as it is changing rapidly to achieve Qatar's National Vision 2030 as the framework within which national strategies and implementation plans can be developed.

\section{Literature review}

\subsection{National culture values}

Hofstede 1980-2001 introduces a unique and useful classification system to understand national culture and defined culture as "the collective programming of the mind; that distinguish the members of one group from another. According to Hofstede "...programming starts within the family; at school, at the workplace, and in both the local and extended living community". The first four dimensions of Hofstede were conceived from the results of an attitude survey administered to 116,000 IBM employees in 40 different countries (Hofstede, 1980). The fifth dimension (long term versus short-term orientation) was added later through the joint efforts of Hofstede and Bond (1988). The five national culture dimensions proposed by Hofstede are:

Power Distance (PDI) the central concept of power distance is defined as "the extent to which the members of a society accept that power in institutions and organizations is distributed unequally" (Hofstede, 2001).More precisely, it is a measure to determine the "interpersonal power" or influence between a boss and a subordinate in a hierarchy, as perceived by the subordinate (Hofstede, 2001).

Uncertainty Avoidance (UAI) it refers to the extent that members of that culture feel comfortable with unknown situations (Hofstede, 2001). It explicit the degree to which individuals deals with the uncertainty and ambiguity in life. This dimension demonstrates "the degree to which members of a society feel uncomfortable with uncertainty and ambiguity, leading them to support beliefs promising certainty" (Hofstede, 2001).

Individualism versus Collectivism (IDV) is the degree to which people in societies prefer to act as individuals rather than as members of groups. Individualism is the belief that everyone is expected to put their own interest ahead of that of the group (Hofstede, 2001).

Masculinity versus Femininity (MAS) refers to dominant gender role patterns in societies (Hofstede, 2001). Men are supposed to be "assertive, tough, and focused on material success, whereas women are supposed to be more modest, tender, and concerned with the quality of work life" (Hofstede \& Hofstede, 2005, p. 120).

Long-Term Orientation (LTO) Hofstede and Bond (1998) explained that cultures with a LTO are characterized by values such as persistence, adaptations of traditions to new circumstances, perseverance toward slow results and the idea that most important events in life will occur in the future. Hofstede defined this dimension as "fostering of virtue oriented towards future rewards, in particular, perseverance and thrift" (2001, p. 359).

\subsection{Readiness for change}

Holt, et al (2007); reproduced new instrument that measures readiness at an individual level because change activities are initiated and carried out by individuals within organizations. Holt et al (2007) proposed a theoretical framework and suggested four constitute readiness to change (appropriateness, management support, and self-efficacy and personal valance). However, this study it restricted to deal with one factor of readiness to change.

Appropriateness of the change refers to the content or the characteristics of a particular change (e.g., outsource to address a discrepancy between the organizations present state and the desired end state). Holt et al 2007 reported, 10 items loaded on this factor. Four of the items were intended to measure the extent to which members felt that a change was needed (i.e., discrepancy), representing the participants' perceptions regarding the legitimacy of a change. Three of the items were designed to measure the extent to which members felt the change would be beneficial to the organization (i.e., organizational valence), focusing on the change's benefits, gained efficiency, and goal congruence. Thus, Factor 1 was labeled appropriateness.

\subsection{Commitment to organizational change}

Herscovitch and Meyer (2002) introduced a three-component model of commitment to organizational change (based on Meyer and Allen, 1991) and demonstrated that employee commitment to a change is a better predictor of behavioral support for a change than is organizational commitment. Herscovitch and Meyer (2002) defined commitment to a change as 'a mindset that binds an individual to a course of action deemed necessary for the successful implementation of a change initiative', and argued that this mindset 'can reflect (a) a desire to provide support for the change based on a belief in its inherent benefits (affective commitment to the change AC), (b) a 
recognition that there are costs associated with failure to provide support for the change (continuance commitment to the change $\mathrm{CC}$ ), and (c) a sense of obligation to provide support for the change (normative commitment to the change NC)' (Herscovitch \& Meyer, 2002, p. 475). Herscovitch and Meyer (2002) argued that affective commitment to change is a stronger binding force than $\mathrm{NC}$ or $\mathrm{CC}$, therefore, this study uses only affective commitment to change.

\section{Theoretical background}

This study investigates the influence of national cultural values as the deeper layer of culture on readiness to change and consequently on commitment to change. The framework in Figurel shows independent variables represented by five dimensions of national cultural typology of Hofstede 1980, and Hofstede and Bond 1988, including ( Power distance (PDI), Individual collectivism (IDV), Uncertainty avoidance (UAI), Masculinity and femininity (MAS), Long term orientation (LTO) influencing the dependent variables affective commitment to change (ACC) and appropriateness readiness to change (ARC).

\section{Research Hypothesis}

This study will introduce the relationship of national culture, commitment to change and readiness to change. It will try to answer the big question whether the national culture is a significant support of an individual commitment to change and readiness to change. The model basically puts forward two propositions: (1) National culture dimensions affect the commitment to change and (2) National culture dimensions affect the readiness to change. Therefore the hypothetical model as explicit in the figure (1) includes these hypotheses:

H1: There is significant relationship between national culture dimensions (power distance, Individualism-Collectivism, uncertainty avoidance, masculinity-femininity and long-term orientation) and commitment to change variable.

H2: There is significant relationship between national culture dimensions (power distance, Individualism-Collectivism, uncertainty avoidance, masculinity-femininity and long-term orientation) and readiness to change variable.

\section{Methods}

The study is quantitative and cross-sectional. Data sources are questionnaires developed to collect information from the participants. The questionnaire includes Hofstede's Value Survey Module 94 to measure national culture dimensions. Commitment to Change measurement will conduct by use Herscovitch and Meyer (2002) Survey and readiness to change will be measured by Holt et al. 2007 (four dimensions theory). Participants (sample size $\mathrm{N}=1037$ ) selected for perform this study are employees of Qataris public organizations from variety levels.

\subsection{Validity and Reliability}

Confirmatory factor analysis was conducted using AMOS 16 software to validate the instruments. Factor loading viewed as regression coefficients in confirmatory factor analysis. The reliability test indicate that Cronbach's Alpha $=.809$ for 40 questions used to collect data.

\subsection{Data Collection Procedures}

The target population is the Qatari public employees and divided into four levels of job category then the respondent selected randomly. The participants was applied the survey by two ways, first paper-based format by distributing the questionnaire personally, second, online format, emails sent to participants including the invitation to participate and link of a web page guide them to the questionnaire. Totally 1037 were usable due to incomplete responses, errors and skipped questions was the most common reason for missing data.

\subsection{Data Analysis}

The data were entered and analyzed using the SPSS 16 and Analysis of Moment Structures (AMOS 16). Data preparation and screening procedures involved assessment of sample size; SEM was utilized to examine interactions among national culture, readiness to change, and Commitment to Change. This research used structural equation modeling for statistical analysis of data collected. (SEM) is a statistical technique which integrates path and factor analysis. Path analysis is a subset of SEM which deals only with measured variables. It is the statistical technique used to examine causal relationships between two or more variables (Kline 2010). SEM refers to a model with multiple indicators for each variable and paths connecting the latent variables. Advantages of SEM compared to multiple regression include more flexible assumptions, the ability to test models with multiple dependents, the ability to model error terms, the ability to test coefficients across multiple between-subjects groups, and the ability to handle difficult data (Stoelting 2009). 


\section{Presentation of Results}

In structural equation modeling, the structural model is a composite of the measurement model and the path model. The measurement model represents a set of observed variables that serve as indicators of a set of latent variables. The path model describes (usually causal) relationships between the latent variables. Because of the primary objective of SEM is to test a specified path model of national culture influence readiness to change and consequently commitment to change variables. A result presents the path analysis of the hypothesized model of national cultural, affective commitment to change and readiness to change.

\subsection{Measurement Model}

Measurement models are created and tested using confirmatory factor analysis (CFA) to evaluate the constructs validity of this study, including five exogenous variables (Five dimensions of National culture ), and endogenous variables commitment to change (affective commitment to change) and readiness to change (appropriateness readiness to change). This model is submitted to structural equation modeling (SEM) analysis in order to valuate constructs validity of the measurement approach adopted in the study. The CFA is conducted using ratio of chi-square to degree of freedom and fit indices (CFI, GFI and RMSEA) to indicate adequate and measures of model fit.

\subsection{Evaluation of Model Fit}

- Chi-Square: for this model was 3610,607 with degree of freedom=712, (p. <.001). Chi-square well known of its sensitivity to sample size (Kline, 2010).

- The goodness of fit index (GFI), is high at GFI = .826 — which marks the highest point of "adequate fit" (Byrne, 2010). GFI values close to 1 indicate a very good fit.

- Comparative Fit Index: $(\mathrm{CFI}=.771)$ which assesses the relative improvement in fit of the proposed model with the independence model which assumes "zero population covariance among the observed variables" (Kline, 2010, p.140). CFI close to 1 indicate a very good fit.

- Root Mean Square Error of Approximation (RMSEA): represents the "degree of misfit per degree of freedom" (Byrne, 2010) and is a "population based" fit index that measures "badness-of-fit" (Kline, 2005, p. 138). RMSEA estimates the amount of error of approximation "per model degree of freedom and takes sample size into account" (p.139). RMSEA $=.063$ (95\% confidence) indicating a very poor good model fit, and would be classified as "consistent... with the hypothesis of poor approximate fit" (Kline, 2010, 139).

The initial results of this hypothetical model fit indicate the poor of fit, so that the model needs more modification to be fit, therefore the next step aim to increase model fit by removing the items which didn't reach the acceptance factor loading value. According to Hair (2010) the factor loading should be more than 0.3 as large sample size. Therefore the model needs more modification to be fit, therefore the next step aim to increase model fit by removing the items which didn't reach the satisfied factor loading.

\subsection{Model Re-specification}

As recommended by Schumacker and Lomax (2004) all modifications made were theoretically meaningful and based on previous empirical literature. Basing on the model fit estimation after modifications were made in figure 7, the hypothesized model was a good fit to the data based on statistically significant fit tests $(\chi 2=$ $1232.648, \mathrm{df}=372, \mathrm{RMSEA}=.047, \mathrm{CFI}=.922, \mathrm{GFI}=.926$ ). Thus, the values was considered to be adequate and provided greater confidence that this estimate is correct. Accordingly, it was concluded that the model cannot be improved any further.

\subsection{Structural Model}

The first objective of the structural model analysis is to test the empirical validity of the proposed paths as well as to ascertain the goodness of fit of the overall model. Path analysis in SEM is a powerful analytical tool that is well-suited to the evaluation of complex models. Maximum Likelihood Estimation is a full-information estimation method that estimates parameters of all relationships in the model simultaneously As well as the significance testing of hypotheses (Kline, 2010). The results of the path analysis of national cultural, commitment to change and readiness to change showed in Figure3.

\subsection{Testing of the hypotheses}

Basing on the findings presented in the final model in Figure 4 the hypothesis testing of the path model can be summarized in the Table 1. 


\section{Discussion}

The results of this investigation suggest that the national culture dimensions, (PDI, IDV, MAS,) have significance relationship with affective commitment to change. National culture dimensions, (IDV, UAI, and LTO) have significance relationship with affective commitment to change through appropriateness readiness to change (ARC). These findings can be discussed as the following points:

First, the independent variable PDI is strongly and negatively related to affective commitment to change (regression coefficient $=-.19, \mathrm{p}<.001$ ). According to the results of this study, Qatar distinguished as low power distance culture, in contrast to Hofstede's results 1980 of the Arabic countries. The reason behind the negative relationship between PDI and ACC is, as we previously explained, that affective commitment to change is defined as a desire to provide support for the change based on a belief in its inherent benefits (Herscovitch \& Meyer (2002). The central concept of power distance is defined as "the extent to which the members of a society accept that power in institutions and organizations is distributed unequally" (Hofstede, 2001, p. 831). More precisely, it is the influence between a boss and a subordinate in a hierarchy, as perceived by the subordinate, so that logically this concept can't produce individual desire to support change, although this dimension consider low PDI but still expressing the distance between high level and lower level of people.

Second, individualism is strongly and positively related to commitment to change (ACC) (regression coefficient $=.11, \mathrm{p}<.001$ ). As previously explained that Individualism is the degree to which people in societies prefer to act as individuals rather than as members of groups. The current study's findings suggest high IDV score in Qatar and according to Hofstede (2001), the more economically developed countries, score closer to the individualist end of this dimension. Hofstede (2001, p. 253) argues that increasing national wealth leads to greater individualism because increased resources reduce dependence on the group.

Third masculinity (MAS) is significantly and positively related to affective commitment to change ACC (regression coefficient $=.11, \mathrm{p}<.001$ ). The analysis pertaining to the potential influences of the cultural dimension of masculinity revealed that Qataris demonstrate low level of masculinity, which means according to Hofstede 2001, Low MAS individuals of this society works in order to live. Hofstede (2001) found that there was a negative correlation between wealth, educational levels, age, and masculinity scores. As Hofstede (2001) has indicated, masculinity scores drop as a population ages and becomes more prosperous. It's well known that the tribal society system in Qatar increases femininity and consequently strengthens the binds among people.

Fourth, uncertainty avoidance was found to have no association with the degree of commitment to change and it is worthy mentioned that the scored of Qatar with UAI value is relatively high. Obviously, UAI refers to the extent that members of that culture feel comfortable with unknown and to what extent the individuals deal with the uncertainty and ambiguity in life (Hofstede, 2001). This findings in line with the previous literature (e.g., Geletkaycz, 1997; Shnieder, 1989; Robertson, Al-Khatib, \& Al-Habib, 2002), values of high uncertainty avoidance should be expected to lead to less willingness for embracing change.

Fifth long term orientation (LTO) has no significance influence on affective commitment to change (ACC). The findings of the current study describe the Qatar culture as low score based on Hofstede's calculation guidelines for this dimension. Hofstede defined this dimension as "fostering of virtue oriented towards future rewards, in particular, perseverance and thrift" (2001, p. 359). The low LTO score indicates that the participants in the current sample value more immediate gratification of their needs and have a much stronger focus on spending, analytic thinking.

Furthermore, national culture dimensions, (PDI, IDV, UAI, and LTO) have significance relationship with readiness to change (appropriateness ARC). These findings can be discussed as the following points:

First, the independent variable Power distance (PDI) was not related to ARC significantly. In fact, it's not surprising that PDI doesn't support the employee readiness to change because the nature of this dimension which reflect the distance of power between high and low level of employees. Second, individualism (IDV) is significantly related to appropriateness readiness to change (ARC). Moreover, people in individualist countries are more likely to look out for their self-interest. Therefore employees would refrain from engaging in resistance behaviors. Thus, individualist would likely exhibit higher levels of ARC. Third, uncertainty avoidance was found to have strong and positive association with appropriateness readiness for change ARC and it deserve to be mentioned that in spite of the scored of Qatar with UAI value is relatively high but the influence of UAI on ARC was significant. Fourth: The result of the current study shows that the cultural dimension MAS has a significant influence on ARC. Fifth: the results of the current study reveals that long term orientation LTO influences ARC, it observed there is a significant influence of LTO on ACC could be happen. 


\section{Conclusions}

The motivation of this study was the lack of empirical evidence regarding the relationship between national culture dimensions and readiness to change and commitment to change. Using a well known Hofstede culture classification, this study validates the importance of a cultural perspective in explaining employee support to change initiatives. Another contribution of this research study was growing empirical base of literature on culture and organizational change studies. The findings of this study support the previous studies like Rangarajan (2004), who considers organizational readiness for change as a condition impacted by a variety of organizational antecedent variables such as culture. The results from data analysis show partial support for a relationship between national culture dimensions and individual readiness to change as well as commitment to change. The findings suggest that individualism practices have strongly encourage individual readiness and commitment to change practices. The findings also pointed out that uncertainty avoidance values increase levels of change phobia. Therefore, policy makers should establish an institutional system to rationalize and systemize mechanisms that contribute to reveal the ambiguity and make the change plans as clearer. Focusing on readiness for change variable can reduce this void.

The findings of this study provide a diagnostic framework of the cultural determinants of readiness and commitment to change. Therefore, organizational change leaders can use these results to guide them in adopting a strategic perspective that concern the dominant national culture to improve organizational change implementation. For example, societies with high uncertainty avoidance practices should adopt long-term transformation programs that emphasize institutional policies to improve the presence of uncertainty avoidance practices.

In summary, predicting organizational behavior toward change using cultural values is important for leaders of change initiatives. It also helps organizations adopt proper strategies with regard to given cultural values in order to overcome the attitudes of resistance to change.

\section{Limitations and future research}

The ability to generalize the findings is limited to the project context, where the data of cultural values exclusive from Qatar state and usually the cultural values are limited to certain region. Several items of national culture values were dropped due to their low-level factor loading values for convergent validity. Replication of this research can be done with using new dimensions of national culture and not restricted to Hofstede's five dimensions.

\section{References}

Abbott, G. N., White, F. A., \& Charles, M. A. (2005). Linking values and organizational commitment. Journal of occupational and organizational psychology, 78(4), 531-551. http://dx.doi.org/10.1348/096317905X26174

Fedor, D.B, Caldwell, S., \& Herold, D. M. (2006). The effects of organizational changes on employee commitment: A multilevel investigation. Personnel Psychology, 59 (1), 1-29. http://dx.doi.org/10.1111/j.1744-6570.2006.00852.x

Geletkanycz, M. (1997). The Salience of 'Culture's Consequences': The Effect of Cultural Values on Top Executive Commitment to the Status Quo. Strategic Management Journal, 18, 615-634. http://dx.doi.org/10.1002/(SICI)1097-0266(199709)18:8<615::AID-SMJ889>3.0.CO;2-I

Hair, J.F. Jr, Black, W.C., Babin and Anderson, R.E. (2010). Multivariate data analysis. (7th Edition.). Pearson Prentice Hall.

Herscovitch, L., \& Meyer, J. P. (2002). Commitment to organizational change: Extension of a three-component model. Journal of applied psychology, 87(3),

Hofstede, G. (1980). Culture's Consequences: International Differences in Related Values. Sage Publications, Beverly Hills, CA.

Hofstede, G. (2001). Culture's consequences: Comparing values, behaviors, institutions and organizations across nations, (2nd ed.). Thousand Oaks, CA: Sage Publications,

Hofstede, G., \& Bond, M. (1988). The Confucius Connections: From Cultural Roots to Economic Growth. Organizational Dynamics, 16(4), 5-21. http://dx.doi.org/10.1016/0090-2616(88)90009-5

Hofstede, G., \& Hofstede, G. J. (2005). Cultures and Organizations: Software of the mind: Intercultural cooperation and its importance for survival. McGraw-Hill: New York.

Holt, D. T., Armenakis, A. A., Feild, H. S., \& Harris, S. G. (2007). Readiness fororganizational change: The 
systematic development of a scale. The Journal of Applied Behavioral Science, 43(2), 232-255. http://dx.doi.org/10.1177/0021886306295295

Iverson, Colin S. McLeod, \& Peter J. Erwin. (1996). The role of employee commitment and trust in service relationships. Marketing Intelligence \& Planning, Vol. 14 Iss: 3 , pp.36 $\quad$ - 44. http://dx.doi.org/10.1108/02634509610117348

Judge, C.J. Thoresen, V. Pucik and T.M. Welbourne. (1999). Managerial coping with organizational change: A dispositional perspective. Journal of Applied Psychology, 84, 107-122. http://dx.doi.org/10.1037/0021-9010.84.1.107

Kesterson, R., \& Broome, S. (2005, July). Islands of change. $T+D$, 59(7), 48-50.

Klein and Sorra, K.J. Klein and J.S. Sorra. (1996). The challenge of innovation implementation. Academy of Management Review, 21, 1055-1080.

Klein, K.J. Klein, A.B. Conn and J.S. Sorra. (2001). Implementing computerized technology: An organizational analysis. Journal of Applied Psychology, 86 (2001), pp. 811-824. http://dx.doi.org/10.1037/0021-9010.86.5.811

Kline, R. (2010). Principles and practice of structural equation modeling. The Guilford Press.

Meyer, J. P., \& Allen, N. J. (1991). A three-component conceptualization of organizational commitment. Human Resources management review, 1, 61-89. http://dx.doi.org/10.1016/1053-4822(91)90011-Z

Parish J. T., Cadwallader S., \& Busch P. (2008). Want to, need to, ought to: employee commitment to organizational change. Journal of Organizational Change Management, 21, (1), 32-52. http://dx.doi.org/10.1108/09534810810847020

Rangarajan, D., Chonko, L. B., Jones, E., \& Roberts, J. A. (2004). Organizational variables, sales force perceptions of readiness for change, learning, and performance among boundary-spanning teams. Industrial Marketing Management, 33(4), 289-305. http://dx.doi.org/10.1016/S0019-8501(03)00072-5

Robertson, C., Al-Khatib, J., \& Al-Habib, M. (2002). The Relationship between Arab Values and Work Beliefs: An Exploratory Examination. Thunderbird International Business Review, 44, 583-601. http://dx.doi.org/10.1002/tie.10036

Schneider, S. (1989). Strategy Formulation: The Impact of National Culture. Organization Studies, 10, 149-168. http://dx.doi.org/10.1177/017084068901000202

Schumacker, R. E., \& Lomax, R. G. (2004). A beginner's guide to structural equation modeling. (2nd ed.). Mahwah, N.J.: Lawrence Erlbaum Associates.

Stoelting, Ricka. (2009). Structural equation modeling/path analysis. [Online] Available: http://userwww.sfsu.edu/ efc/classes/biol710/path/SEMwebpage.htm.

Trompenaars, A., \& Hampden-Turner, C. (1998). Riding the waves of culture: Understanding cultural diversity in global business. McGraw Hill. 
Table 1. Hypotheses Testing Results

\begin{tabular}{|c|c|c|c|}
\hline No & Hypothesis & $\begin{array}{l}\text { Supported } \\
\text { or Not }\end{array}$ & Result \\
\hline \multirow{5}{*}{ H1 } & $\begin{array}{l}\text { Power distance significantly related with } \\
\text { affective commitment to change }\end{array}$ & $\mathrm{S}$ & $\begin{array}{c}\text { PDI and } \mathrm{ACC}=-.19, \\
\mathrm{p}<.01, \text { two-tailed }\end{array}$ \\
\hline & $\begin{array}{l}\text { Uncertainty Avoidance insignificantly related to } \\
\text { affective commitment to change }\end{array}$ & NS & $\mathrm{UAI}$ and $\mathrm{ACC}=-.01$ \\
\hline & $\begin{array}{l}\text { Individualism significantly related to affective } \\
\text { commitment to change }\end{array}$ & $\mathrm{S}$ & $\begin{array}{l}\text { IDV and } \mathrm{ACC}=.11, \\
\mathrm{p}<.01, \text { two-tailed }\end{array}$ \\
\hline & $\begin{array}{l}\text { Masculinity significantly related to affective } \\
\text { commitment to change }\end{array}$ & $\mathrm{S}$ & $\begin{array}{l}\text { MAS and } \mathrm{ACC}=.08, \\
\mathrm{p}<.05 \text { two-tailed). }\end{array}$ \\
\hline & $\begin{array}{l}\text { Long-Term Orientation is insignificantly related } \\
\text { to affective commitment to change }\end{array}$ & NS & LTO and $\mathrm{ACC}=.02$ \\
\hline \multirow{5}{*}{ H2 } & $\begin{array}{l}\text { Power distance (PDI) is insignificantly related } \\
\text { to Appropriateness Readiness to change (ARC). }\end{array}$ & NS & $\mathrm{PDI}$ and $\mathrm{ARC}=.05$ \\
\hline & $\begin{array}{l}\text { Uncertainty Avoidance is significantly related } \\
\text { to Appropriateness Readiness to change (ARC). }\end{array}$ & $\mathrm{S}$ & $\begin{array}{c}\text { UAI and } \mathrm{ARC}=.14 \\
\mathrm{p}<.01, \text { two-tailed }\end{array}$ \\
\hline & $\begin{array}{l}\text { Individualism is significantly related to } \\
\text { Appropriateness Readiness to change (ARC). }\end{array}$ & $\mathrm{S}$ & $\begin{array}{c}\text { IDV and ARC }=.15, \\
\mathrm{p}<.01, \text { two-tailed }\end{array}$ \\
\hline & $\begin{array}{l}\text { Masculinity is significantly related to } \\
\text { Appropriateness Readiness to change (ARC). }\end{array}$ & $\mathrm{S}$ & $\begin{array}{c}\text { MAS and ARC }=.10 \\
\mathrm{p}<.05\end{array}$ \\
\hline & $\begin{array}{l}\text { Long-Term Orientation is significantly related } \\
\text { to Appropriateness Readiness to change (ARC). }\end{array}$ & $\mathrm{S}$ & $\begin{array}{l}\text { LTO on } \mathrm{ARC}=.11 \\
\mathrm{p}<.01, \text { two-tailed }\end{array}$ \\
\hline
\end{tabular}

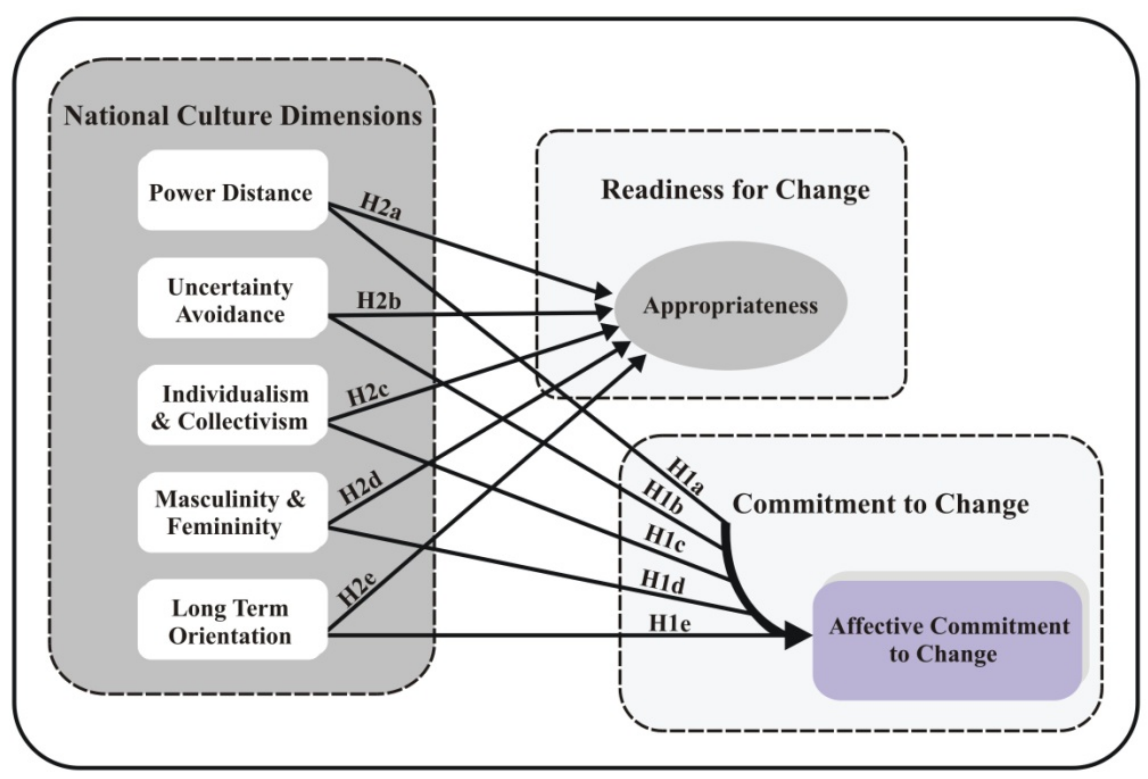

Figure 1. Theoretical framework 


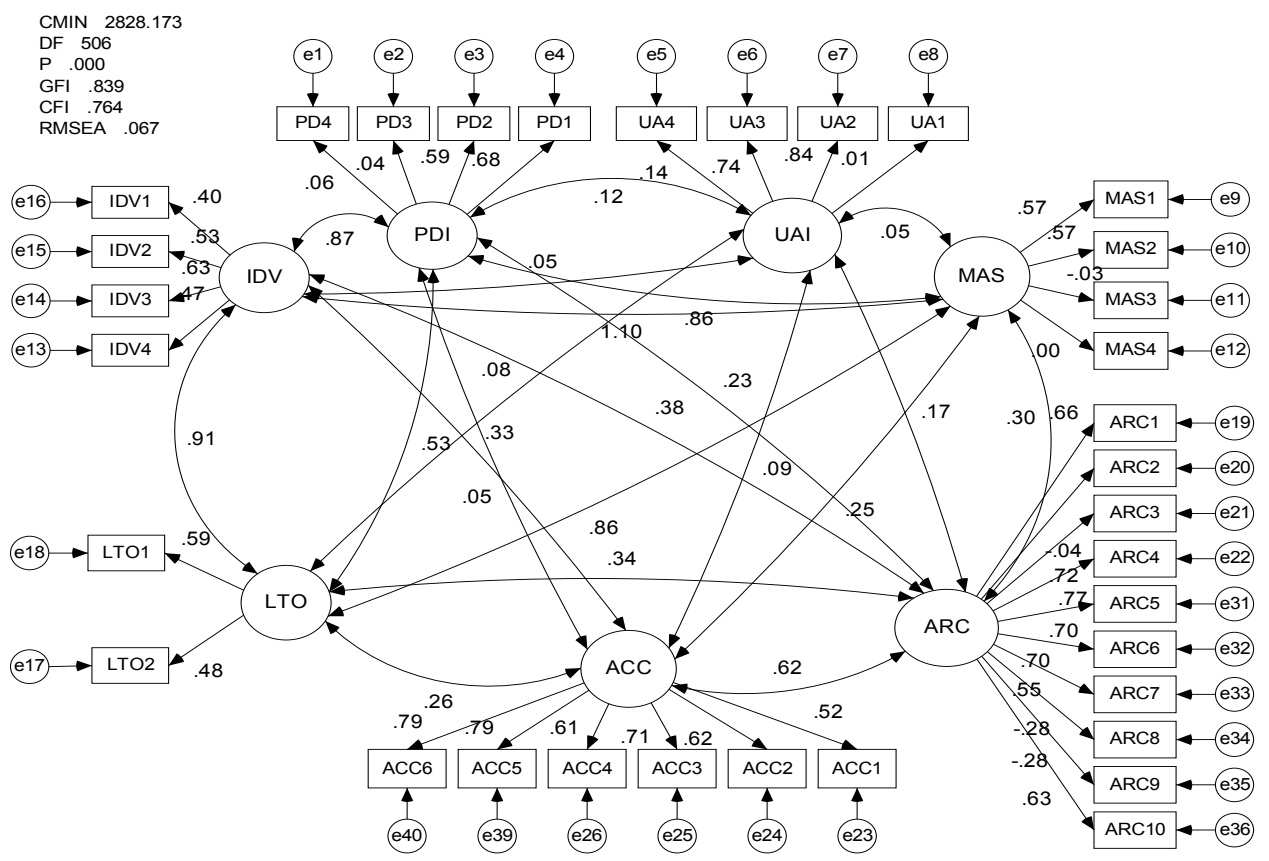

Figure 2. Measurement model Exogenous, observed, and endogenous variables in the SEM

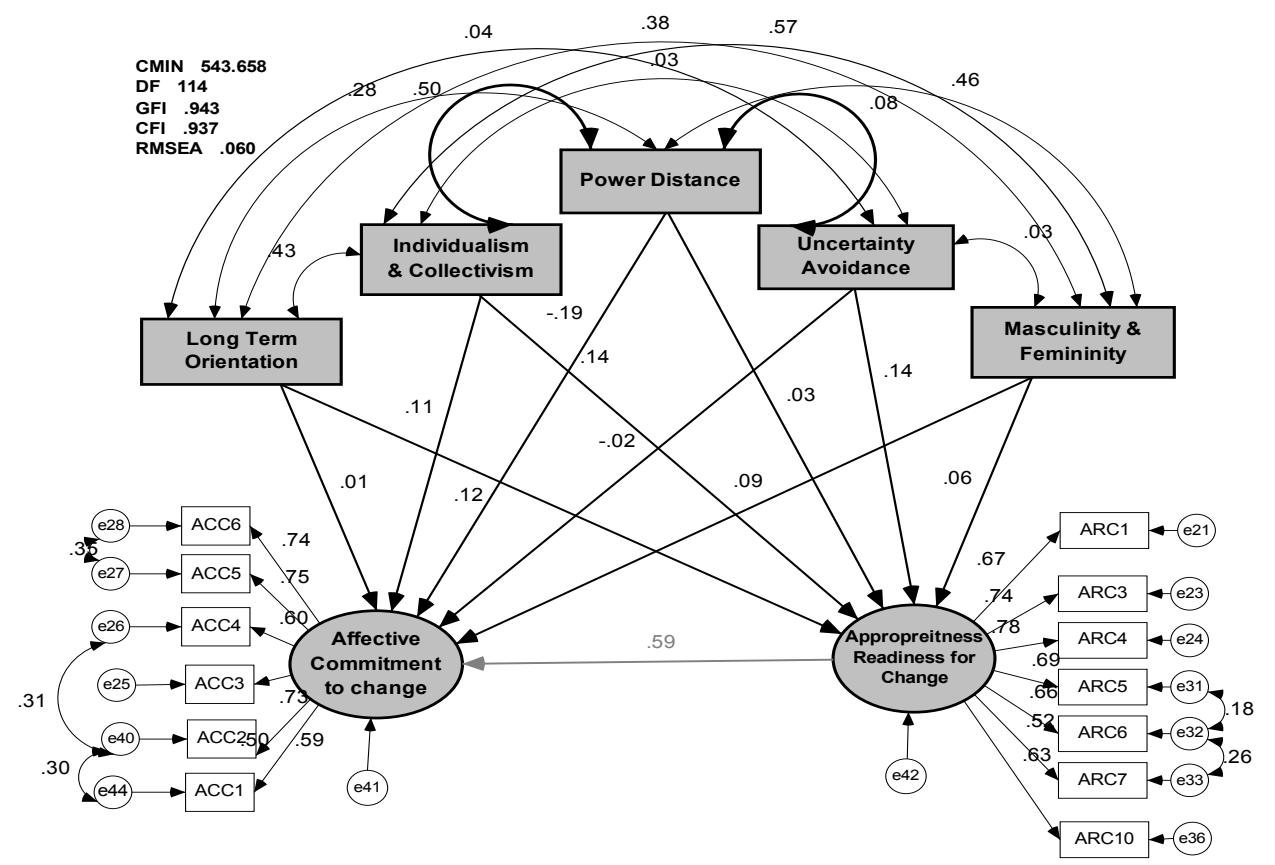

Figure 3. Structural Model of Exogenous and Endogenous Variables 


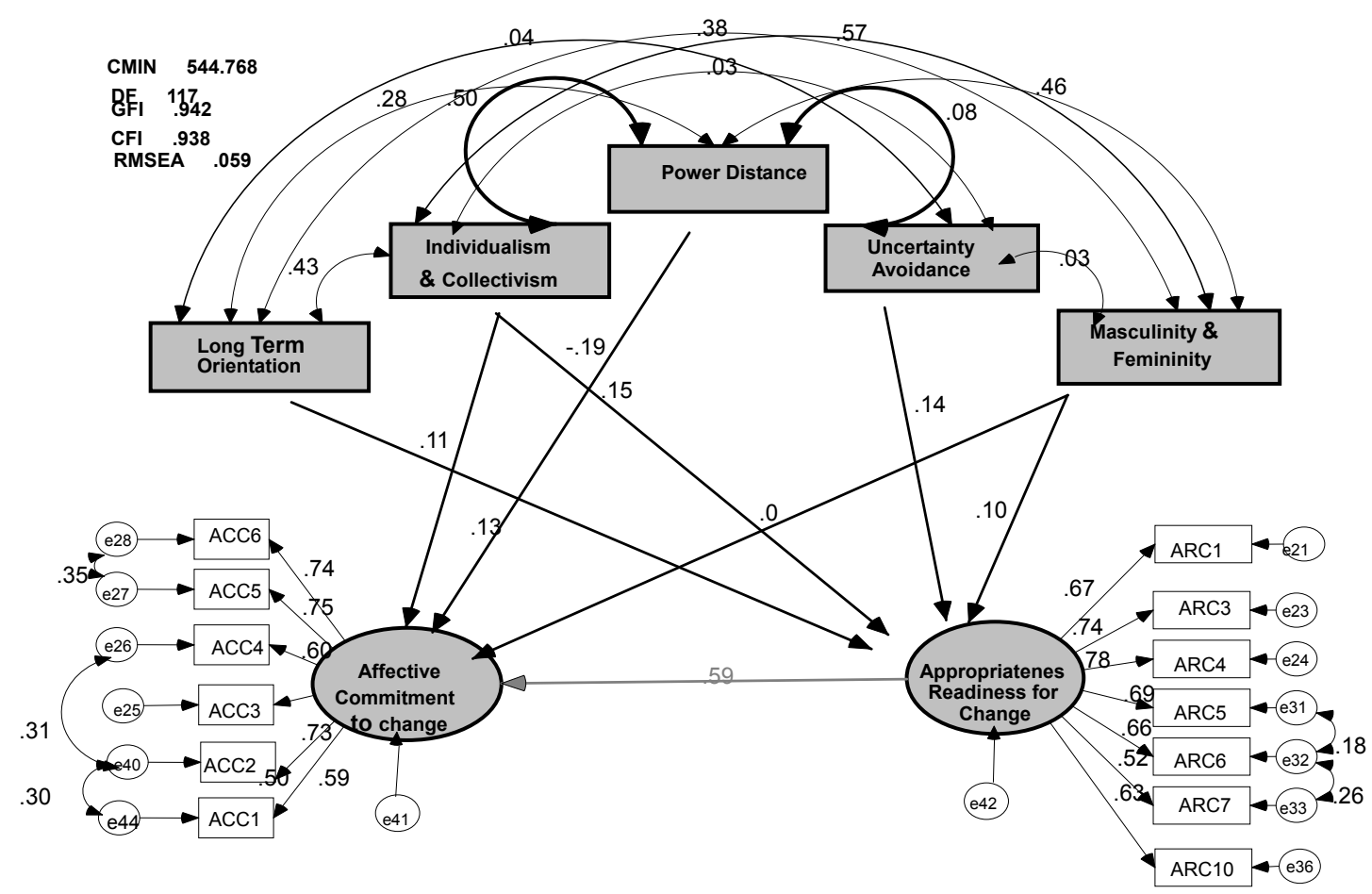

Figure 4. Final Model 